\title{
Meningitis aséptica por virus parotídeo asociada a la vacuna
}

\author{
Aseptic meningitis due to mumps vaccine. Case report and review of the literature
}

\author{
Aline Jorquera L. ', Daniela Ugarte C. ', Carmen Avilés L., ${ }^{1,2}$ y Luis Delpiano M $^{1,2}$
}

'Servicio de Pediatría, Hospital Clínico San Borja Arriarán. Santiago, Chile.

Unidad de Infectología, Servicio de Pediatría, Hospital Clínico San Borja Arriarán. Santiago, Chile.

Los autores declaran no tener conflictos de interés para esta publicación.

Sin financiamiento.

Recibido: 23 de abril de 2020 / Aceptado: 26 de octubre de 2020

\section{Resumen}

Comunicamos el caso de un lactante mayor previamente sano, que luego de tres semanas de recibir la vacuna SPR (sarampión, parotiditis, rubeola) presentó fiebre, aumento de volumen parotídeo y compromiso de conciencia. Se diagnosticó una meningitis aséptica, con pleocitosis en el LCR de predominio mononuclear, detectándose virus parotídeo en LCR por biología molecular. En el Instituto de Salud Pública de Chile se realizó serología (IgM e IgG) que resultó positiva. La muestra de saliva confirmó la etiología por virus parotídeo con genotipo $\mathrm{N}$. La evolución fue favorable, sin secuelas al seguimiento a seis meses. Ante esta situación clínica, se revisó la información respecto a la asociación y causalidad de esta entidad clínica y vacuna SPR, focalizado en diferentes cepas del virus parotiditis.

Palabras claves: meningitis aséptica; parotiditis; vacuna tresvírica; cepa Leningrad-Zagreb.

\section{Introducción}

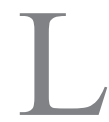

a parotiditis es una infección aguda generalmente benigna y autolimitada de la glándula parótida causada por el virus parotídeo. Corresponde a un virus ARN monocatenario del género Rubulavirus, familia Paramyxoviridae, con afinidad por el epitelio glandular. Se caracteriza por codificar ocho proteínas: nucleoproteína $(\mathrm{N})$, fosfoproteína $(\mathrm{P})$ y $(\mathrm{V})$, proteína de matriz $(\mathrm{M})$, proteína hidrofóbica pequeña $(\mathrm{SH})$, proteína larga $(\mathrm{L})$, proteína de fusión $(\mathrm{F})$ y hemaglutinina-neuroaminidasa $(\mathrm{HN})$, estas dos últimas implicadas en la neurovirulencia y principales objetivos de la inmunidad humoral ${ }^{1}$. Existen al menos 12 genotipos, desde la A hasta la $\mathrm{N}$ (excluyendo

\begin{abstract}
We report the case of an older infant with no prior morbidity that approximately 3 weeks after receiving MMR vaccination (measles, mumps, rubella) was hospitalized for feverish symptoms, increased parotid volume and compromised consciousness. Aseptic meningitis was diagnosed, detecting pleocytosis in the CSF, predominantly mononuclear, and confirming by molecular biology, presence of parotid virus in CSF. A study was carried out by the Institute of Public Health of Chile, where serology (IgM and $\operatorname{IgG}$ ) was positive. Saliva sample confirmed the etiology of parotid virus with genotype N. The evolution was favorable and at 6-month follow-up, there were no sequelae. Given this clinical situation, information regarding the association and causality of this clinical entity and the MMR vaccine, focused on different strains of the mumps virus, was reviewed.

Key words: aseptic meningitis; mumps; MMR vaccine; Leningrad Zagreb strain.
\end{abstract}

E y M) basados en las secuencias de nucleótidos de genes pequeños hidrófobos (SH) que varían según la zona geográfica. En Chile, la circulación actual corresponde al virus parotídeo genotipo $\mathrm{G}$ y N (este último incluido en vacuna Leningrad-Zagreb, año 2009)2.

El virus parotiditis tiene reservorio exclusivo humano. Se presenta en primavera e invierno y produce brotes epidémicos cada dos a cinco años, generalmente en niños de 5 a 9 años. El mecanismo de transmisión es por gotitas, contacto directo o por fómites contaminados. El periodo de incubación es de 15 a 24 días y el contagio ocurre desde uno a dos días previos al inicio de los síntomas hasta nueve días posteriores al aumento de volumen parotídeo. En su patogenia, el virus se replica en la mucosa nasofaríngea y en los linfonodos regionales, pudiendo

\section{Correspondencia a:}

Aline Jorquera L.

alinejorqueral@gmail.com 
mantenerse como una infección localizada o resultando en una viremia transitoria con diseminación a distancia ${ }^{3}$. A pesar de la alta frecuencia de síntomas sistémicos, la detección del virus en la sangre es infrecuente, no así en saliva en que puede detectarse desde una semana antes hasta una semana después del inicio de la inflamación parotídea ${ }^{4}$.

Las manifestaciones clínicas se observan en $70 \%$ de los casos y de ellos, 95\% muestra compromiso parotídeo, siendo $90 \%$ bilateral $^{1}$. El compromiso extra-parotídeo es más frecuente en adolescentes y adultos como complicación de la infección. Respecto al sistema nervioso central, corresponde a la afectación sistémica más común tras el compromiso de las glándulas salivales. La meningitis aséptica, caracterizada por la aparición súbita de signos y síntomas de meningitis, LCR inflamatorio y ausencia de microorganismos al Gram o cultivo, se presenta en menos de $10 \%$ de los casos, tras cinco días de iniciado el compromiso parotídeo, con una duración de siete a diez días. Los cambios en el LCR se caracterizan por pleocitosis de predominio mononuclear, con glucorraquia y proteinorraquia normal ${ }^{4,5}$. Las secuelas a largo plazo son poco comunes, pero pueden presentarse como parálisis, hidrocefalia y sordera. La tasa de mortalidad varía entre 1,6 y 3,8 por 100.000 habitantes, generalmente asociada a encefalitis 6 .

Si bien el diagnóstico es primordialmente clínico, en zonas con altas tasas de vacunación y baja incidencia de la enfermedad se recomienda la confirmación por laboratorio. El uso de técnicas moleculares como RTRPC (reacción de polimerasa en cadena con transcriptasa inversa) en diferentes fluidos (saliva y LCR) tiene alta sensibilidad y especificidad. En lugares con alta cobertura de inmunización se recomienda la RT-RPC en saliva, idealmente los primeros tres días de la enfermedad, con genotipificación. La serología con detección de IgM es un buen método de confirmación, sin embargo, en personas vacunadas condiciona un alto número de falsos negativos (elevación transitoria) requiriendo repetir la muestra o complementar con IgG (seroconversión o elevación de títulos). La medición de IgG debe evaluarse con cautela en paciente vacunados quienes probablemente resulten seropositivos $^{3,7}$.

Previo a la introducción de la vacuna contra la parotiditis en los programas de inmunización, 95\% de los adultos presentaban marcadores serológicos de exposición. En Chile, se introdujo en el programa de inmunizaciones como vacuna tresvírica en el año 1990, con una disminución importante de la tasa de incidencia de 225 por 100.000 a menos de 10 por 100.000 habitantes $^{2}$.

En los últimos años han aparecido brotes de parotiditis en población adulta vacunada en los que se postula una falla en la vacunación primaria o secundaria, neutralización cruzada incompleta entre cepas vacunales y salvajes, cambios en la formulación de vacunas e incluso una pérdida de inmunidad como consecuencia del cese de vacunación en algunos países (Japón retiró la vacuna de su programa de inmunizaciones tras un aumento de casos de meningitis aséptica $)^{4}$. La cobertura necesaria para lograr la inmunidad de rebaño y evitar brotes es de 88 a $92 \%$.

Las vacunas disponibles incluyen diferentes preparados con variabilidad en las cepas. Existen más de 10 vacunas disponibles: Jeryl Lynn, UrabeAm9, Hoshino, Torii, Leningrad-Zagreb y Leningrad-3, entre otras ${ }^{8}$. En Chile, la vacuna incluida hasta el año 2009 en el PNI fue UrabeAM9 (genotipo B), y actualmente la vacuna disponible es Leningrad-Zagreb (genotipo $\mathrm{N})^{3}$.

Los eventos adversos reportados para la vacuna parotiditis incluyen cuadros leves: reacciones locales en sitio de inyección (17 a 30 casos/100 dosis) en general a las 24 $\mathrm{h}$ de inmunización y de 48 a 72 h de duración, parotiditis (1 a 2 casos/100 dosis) entre el día 10-14 de administrada la vacuna y eventos serios como meningitis aséptica.

Presentamos el caso clínico de un lactante mayor con una meningitis aséptica por virus parotídeo asociado a la vacuna.

\section{Caso clínico}

Lactante mayor de 1 año 4 meses previamente sano, procedente de Venezuela, que en febrero de 2019 consultó en el servicio de urgencias (SU) por fiebre de dos días de evolución y aumento de volumen parotídeo derecho. Se realizó el diagnóstico de una parotiditis, egresando con indicación de anti-inflamatorios. Evolucionó con persistencia de los síntomas, agregándose vómitos y diarrea, por lo que fue reevaluado en el SU diagnosticándose una gastroenteritis aguda, derivándose nuevamente a su domicilio con manejo sintomático. Persistió febril y con vómitos; al séptimo día de evolución presentó cefalea, fotofobia e irritabilidad, por lo que consultó en SU dónde se constató febril, con hemodinamia estable, decaído, somnoliento e hiporeactivo. Al examen físico segmentario se encontró un aumento de volumen parotídeo leve bilateral, sin signos meníngeos. En los exámenes de laboratorio destacaba un hemograma con hemoglobina $12,9 \mathrm{~g} / \mathrm{dl}$, 8940 leucocitos $/ \mathrm{mm}^{3}$ (linfocitos 62\%), 239.000 plaquetas/ $\mathrm{mm}^{3}$, PCR $1 \mathrm{mg} / \mathrm{dl}$, glicemia $81 \mathrm{mg} / \mathrm{dl}$, función renal, hepática, amonio y ácido láctico en rangos normales. Por compromiso de conciencia cuantitativo se realizó una tomografía cerebral (TC) sin contraste informado como normal y posteriormente se efectuó una punción lumbar (PL) que dio salida a LCR citrino, con 650 leucocitos (100\% mononucleares), glucosa $33 \mathrm{mg} / \mathrm{dl}$, proteínas 82 $\mathrm{mg} / \mathrm{dl}$, sin observación de bacterias a la tinción de Gram y panel molecular Filmarray ${ }^{\mathcal{O}}$ LCR negativo.

Se internó en la Unidad de Intermedio con el diagnós- 
tico de una meningoencefalitis aguda. En la anamnesis se rescató el antecedente de vacunación tresvírica 19 días previo al inicio de los síntomas, por lo que se notificó como un evento supuestamente atribuible a vacunación o inmunización (ESAVI). Se realizó una RT-RPC en LCR (Light Cycler-Roche) para virus parotídeo que resultó positivo.

Se enviaron muestras de sangre, orina y saliva al Instituto de Salud Pública (ISP) de Chile, donde se efectuó serología IgG e IgM para virus parotídeo resultando ambas positivas, así como también IgM para sarampión y rubeola de la misma muestra. Se realizó la genotipificación desde la muestra de saliva resultando el genotipo N, correspondiente al genotipo vacunal.

Durante su permanencia en el hospital evolucionó estable, afebril a las $24 \mathrm{~h}$ de ingreso y con una rápida regresión del aumento de volumen parotídeo. Tanto el examen neurológico realizado por neurólogo al segundo día como el electroencefalograma fueron normales. Fue dado de alta a los cinco días del ingreso, sin secuelas pesquisadas al seguimiento de seis meses en el policlínico de neurología e infectología.

Aproximadamente dos meses después del egreso del paciente hubo una reunión con profesionales del ISP y de la OPS para analizar el caso clínico, concluyendo el caso como una meningitis por virus parotídeo asociada a la administración de la vacuna.

\section{Discusión}

La infección por virus parotídeo y sarampión eran una causa frecuente de meningitis aséptica en la era pre-vacunación. Si bien las infecciones virales siguen siendo la principal causa de meningitis, el uso de nuevas técnicas moleculares como RPC en LCR, han permitido identificar precozmente varios agentes virales y otros microorganismos de difícil diagnóstico que no eran detectados con las pruebas clásicas: Mycobacterium tuberculosis, Treponema pallidum, entre otros, (todos agentes importantes a considerar dentro del estudio en pacientes con meningitis). Otros diagnósticos diferenciales incluyen infecciones parameníngeas, enfermedades inmunológicas, fármacos e inmunizaciones ${ }^{5}$.

Se presenta el caso clínico de un lactante mayor con diagnóstico de parotiditis que, con registro de vacunación reciente, evolucionó con una meningitis aséptica y en el que se logró certificar el virus parotiditis, genotipo asociado a la vacuna.

Si bien no existe consenso sobre la definición de meningitis aséptica tras inmunización, algunos estudios lo definen como: evidencia clínica de meningitis aguda (fiebre, cefalea, vómitos, fontanela abombada, rigidez de nuca $u$ otros signos de irritación meníngea entre 15 y
35 días post-vacuna tresvírica), pleocitosis linfocitaria, con cultivo y Gram negativo en el LCR y confirmación virológica con determinación molecular de la cepa aislada ${ }^{9}$ (criterios que cumplía nuestro paciente).

La identificación de un patógeno en el LCR en una meningitis es de gran importancia para el clínico, ya que permite dirigir la terapia $\mathrm{y}$, al postular una meningitis aséptica, conlleva la abstención del uso de antimicrobianos. Sin embargo, es infrecuente asociar una etiología identificada en el LCR a una vacuna recientemente administrada.

Para la evaluación de causalidad en el caso presentado, el equipo ESAVI, del Subdepartamento de Farmacovigilancia de Chile, utilizaron los criterios de Brighton Collaboration $^{5,10}$ (criterios definidos por un grupo de expertos para monitorizar los perfiles de seguridad e índices de riesgo para las vacunas) y la evaluación de causalidad de eventos adversos individuales tras inmunización establecidos por la OMS (AEFI) ${ }^{11}$. Nuestro caso cumplía con los criterios de una meningitis aséptica (presentación clínica, LCR con pleocitosis, sin bacterias al Gram y cultivos negativos en LCR) y el tiempo establecido para meningitis post-vacuna (entre 10 y 35 días). La notificación oportuna como sospecha de ESAVI, con posterior confirmación por el ISP como una meningitis aséptica por virus parotídeo asociado a la vacuna (genotipo $\mathrm{N}$ ), llevaron a que un equipo de expertos determinara una causalidad "consistente" con la administración de la vacuna SRP, emitiendo la recomendación de continuar con el esquema vacunación acorde a $\mathrm{PNI}^{12}$.

Las vacunas contra la parotiditis disponibles contienen virus vivos atenuados, ya sea en presentación monovalente o en combinación con otros virus como rubeola, sarampión y varicela. Actualmente, las cepas de la vacuna más utilizadas son: Jeryl Lynn, RIT 4385, Urabe y Leningrad-Zagreb (genotipo A, A, B y N; respectivamente) ${ }^{8}$. Considerando que, aunque existen diferencias antigénicas entre los virus parotídeos, estos son serológicamente monotípicos, por lo que independiente de la cepa (genotipo) utilizada en la formulación de las vacunas disponibles, la protección debería ser adecuada contra la enfermedad dado su capacidad de neutralización cruzada ${ }^{13}$.

El riesgo de compromiso meníngeo secundario a la vacunación tresvírica está documentado en la literatura científica. Se ha descrito un riesgo 5,5 a 38 veces mayor de casos de meningitis aséptica para cepas Urabe, LeningradZagreb y Hoshino comparado a la era pre-vacunación, habitualmente con una evolución benigna y autolimitada ${ }^{5}$. La tasa de meningitis aséptica varía ampliamente probablemente por diferencias en el diseño de los estudios, la definición del caso, la edad de los pacientes o las cepas de las vacunas involucradas ${ }^{14}$. La incidencia de meningitis aséptica para la cepa Leningrad-Zagreb (cepa actualmente utilizada en Chile) varía entre 1 y 90/100.000 dosis admi- 


\section{- rci caso clínico}

nistradas ${ }^{8}$. La tasa nacional reportada por el ISP año 2018 fue de 0,20/100.000 dosis administradas ${ }^{15}$. Considerando que la mayoría de los casos son autolimitados y sin secuelas a largo plazo, podría existir una baja sospecha diagnóstica y por ende, subnotificación como ESAVI y menor tasa de casos reportados en nuestro país.

Una revisión sistemática de Cochrane, sobre efectividad y efectos adversos de la vacuna tresvírica bajo los 15 años, mostró que la efectividad en prevenir la parotiditis tras la administración de al menos una dosis de vacuna tresvírica fue de $69-81 \%$ para cepa Jeryl Lynn y de 70 $75 \%$ para cepa Urabe. Respecto a la meningitis aséptica, se observó mayor riesgo de presentarla entre la tercera y quinta semana tras la inmunización: cepa Urabe Am9 (RR 14,2; IC95\% 7,9-25,7) y cepa Leningrad-Zagreb (RR 22,5; IC95\% 11,8-42,9) a la tercera semana comparado con el control. Las vacunas que contenían cepa Jeryl-Lynn no mostraron asociación significativa con meningitis aséptica ${ }^{16}$. A pesar de que esta revisión incluyó ensayos clínicos aleatorizados, estudios de cohorte y caso-control entre otros, la literatura científica disponible muestra resultados variables en cuanto a tasas de efectividad y seroconversión, probablemente por diferencias en el diseño de los estudios.
Las tasas de meningitis aséptica post-vacuna de parotiditis se presentan en la Tabla 1. Dentro de las teorías que se postulan se encuentran alteraciones en los factores genéticos o secuencias aminoacídicas como posibles responsables del mayor riesgo de neurovirulencia de ciertas cepas vaccinales frente a otras.

Un estudio realizado en Japón demostró que 70\% de los virus parotiditis aislados de pacientes con meningitis aséptica (no asociada a vacuna), carecían de una enzima de restricción (denominada $\mathrm{B} a m \mathrm{HI}$ ) que en su función normal provoca rupturas en sitios específicos de secuencias nucleotídicas en el gen $P$ que codifica la fosfoproteína (involucrada en la transcripción y replicación del genoma). La ausencia de esta enzima podría estar implicada en un mayor riesgo de neurovirulencia. Este mismo fenómeno se observó en la cepa Urabe, presente en la vacuna ${ }^{17}$.

Otros estudios han mostrado que la sustitución de nucleótidos en posiciones específicas, con consiguientes cambios aminoacídicos en la proteína $\mathrm{HN}$ (hemaglutininaneuroaminidasa) o SH (hidrofóbica pequeña) del virus parotiditis, pueden disminuir la capacidad de neutralización cruzada, determinando mayor patogenicidad y mayor riesgo de meningitis ${ }^{18}$. El más estudiado es la sustitución del aminoácido lisina por glicina, en la posición 335 de

\begin{tabular}{|c|c|c|c|c|c|c|}
\hline Cepa & Genotipo & Origen & $\begin{array}{l}\text { Seroconversión } \\
\text { con una dosis }\end{array}$ & Efectividad & Características & $\begin{array}{l}\text { Tasa de meningitis } \\
\text { aséptica por dosis }\end{array}$ \\
\hline Urabe AM9 & B & $\begin{array}{c}\text { 1979, Japón } \\
\text { Cultivos celulares embrión } \\
\text { pollo }\end{array}$ & $92-100 \%$ & $73 \%$ & $\begin{array}{l}\text { Diferentes perfiles de reactogenicidad } \\
\text { Contiene dos cepas diferentes que difieren en un } \\
\text { solo codón del gen de hemaglutinina-neuraminidasa } \\
\text { Retirada de Canadá en } 1990 \text { y de Japón en } 1993\end{array}$ & $90-490 / 10^{6}$ \\
\hline $\begin{array}{l}\text { Jeryl Lynn } \\
\text { (JL) }\end{array}$ & A & $\begin{array}{l}\text { 1967, E.U.A. Cultivos } \\
\text { celulares embrión pollo }\end{array}$ & $80-100 \%$ & $63-96 \%$ & $\begin{array}{c}\text { Dos poblaciones virales; JL-5 Y JL-2. } \\
\text { Considerada segura y poco reactogénica } \\
\text { No hay reportes claros de meningitis asociados a } \\
\text { vacuna }\end{array}$ & $1-10 / 10^{6}$ \\
\hline RIT 4385 & A & Derivada de cepa Jeryl Lynn & $88-98 \%$ & & Perfil de eficacia y seguridad similar a Jeryl Lynn & \\
\hline $\begin{array}{l}\text { Leningrad } \\
\text { Zagreb } \\
\text { (L-Zagreb) }\end{array}$ & $\mathrm{N}$ & $\begin{array}{l}\text { 1972, Croacia } \\
\text { Atenuada desde Leningrad-3 } \\
\text { Cultivos celulares embrión } \\
\text { pollo }\end{array}$ & $89-98 \%$ & $92-99 \%$ & $\begin{array}{l}\text { Reportes de casos de meningitis aséptica } \\
\text { Bajo costo de producción }\end{array}$ & $13-900 / 10^{6}$ \\
\hline $\begin{array}{l}\text { Leningrad-3 } \\
(\mathrm{L}-3)\end{array}$ & $\mathrm{N}$ & $\begin{array}{c}\text { 1950, Unión Soviética. } \\
\text { Cultivo de células de riñón } \\
\text { de cerdo }\end{array}$ & $89-98 \%$ & $92-99 \%$ & Posible transmisión horizontal & $200-1.000 / 10^{6}$ \\
\hline Rubini & A & $\begin{array}{l}\text { 1985, Suiza. } \\
\text { Cultivo en línea celular } \\
\text { diploide humana con pases } \\
\text { sucesivos por huevos de } \\
\text { gallina embrionados }\end{array}$ & $23-95 \%$ & $0-33 \%$ & $\begin{array}{c}\text { Baja efectividad clínica } \\
\text { Larga epidemia en Portugal, Suecia, Italia que con- } \\
\text { dujo a abandono de su uso } \\
\text { OMS no recomienda su uso en programas de inmu- } \\
\text { nización }\end{array}$ & No encontrado \\
\hline
\end{tabular}


la proteína $\mathrm{HN}$, de pacientes con meningitis aséptica post-vacuna con cepa Urabe. Sin embargo, otros autores proponen que esta mutación por sí sola no es suficiente para generar neurovirulencia y que no se pueden descartar los efectos aditivos y/o sinérgicos de otras mutaciones, ya sea en la misma proteína o en otras ${ }^{19}$.

Por otro lado, un estudio realizado en E.U.A, sobre marcadores de atenuación de la cepa Urabe AM9, mostró que a pesar de obtener dos variantes menos virulentas (ensayo en ratas), hubo cambios en los sitios específicos del genoma, determinando heterogeneidad en sus quasiespecies con mayor potencial de ser neurovirulentas ${ }^{20}$. Resultados similares fueron encontrados en el análisis de la vacuna con la cepa Leningrad-Zagreb. Estos resultados, apoyan el hecho de que al contener las vacunas más de un clon vírico atenuado, las hace antigénicamente diferente y con distintos perfiles de seguridad, siendo fundamental el estudio de genotipificación con análisis filogenético para mejor caracterización epidemiológica ${ }^{13}$.

A pesar de la información sobre el mayor riesgo de meningitis aséptica para ciertas cepas vacunales, los estudios no son comparables entre sí por diferencias metodológicas. Es por esto que la OMS establece que todas las preparaciones disponibles para la prevención de la parotiditis son aceptables para su uso en programas de inmunización y que los datos obtenidos de los estudios expuestos no deben interpretarse como una justificación para la suspensión de los programas de inmunización existentes contra la parotiditis ya que, la incidencia y gravedad de la meningitis tras la infección natural excede los riesgos atribuibles a cualquier vacuna actualmente disponible ${ }^{8}$. De ahí entonces que, para nuestro paciente, la recomendación del equipo OPS-ISP fue continuar con el esquema vacunación acorde al PNI.

Si bien cepa Jeryl Lynn es la que presenta menos reportes de meningitis aséptica, es una vacuna costosa en su producción, que pudiese hacerla menos elegible para países como el nuestro. Datos entregados por la OPS en junio 2019 indican que el valor promedio de cada dosis de vacuna cepa Jeryl Lynn es de US \$ 5.59 comparado con US \$ 1.43-2.75 cepa Leningrado-Zagreb (actualmente en nuestro PNI $)^{21}$.

La notificación de un ESAVI es obligatoria desde el año 2010 en nuestro país ${ }^{22}$ para todos los profesionales de la salud. Esto requiere un alto índice de sospecha para evitar la sub-notificación de casos y detectar este tipo de eventos adversos con el objetivo de evaluar la seguridad de las vacunas administradas a nuestra población.

\section{Referencias bibliográficas}

1.- Hviid A, Rubin S, Muhlemann K. Mumps. Lancet 2008; 371: 932-44. doi: 10.1016/S01406736(08)60419-5.

2.- Potin, M. Brotes de parotiditis en pacientes vacunados, interrogantes por resolver. SOCHINF. Noviembre 2018. Disponible en: http://www.sochinf.cl/portal/templates/ sochinf2008/documentos/2018/presentaciones/ congreso/viernes/1.pdf (Fecha de acceso: 20 de febrero de 2020).

3.- Le Corre N, Barría S, López T, MartínezValdebenito C, Contreras A, Ferrés M. Parotiditis en Chile: caracterización clínica y molecular de dos casos en una población altamente inmunizada. Rev Chil Infectol 2018; 35: 198-203. doi: 10.4067/s071610182018000200198 .

4.- Rubin S, Eckhaus M, Rennick L, Bamford C, Duprex W. Molecular biology, pathogenesis and pathology of mumps virus. J Pathol 2015; 235: 242-52. doi:10.1002/path.4445.

5.- Tapiainen T, Prevots R, Izurieta $H$, Abramson J, Bilynsky R, Bonhoeffer J, et al. Aseptic meningitis: Case definition and guidelines for collection, analysis and presentation of immunization safety data. Vaccine 2007; 25: 5793 - 802. doi:10.1016/j. vaccine.2007.04.058.

6.- Principi N, Esposito S. Mumps outbreaks: A problem in need of solutions. J Infect 2018; 76: 503-6. doi: 10.1016/j.jinf.2018.03.002.

7.- Balbi A, Van Sant A, Bean E, Jacoby J. Mumps: Resurgence of a once-dormant disease. JAAPA 2018; 31: 19-22. doi:10.1097/01. JAA.0000532112.90755.41.

8.- World Health Organization. Global vaccine safety. Information Sheet Observed Rate of Vaccines Reactions. Measles, Mumps and Rubella Vaccines. May 2014. Disponible en: https://www.who.int/vaccine_safety/initiative/ tools/MMR_vaccine_rates_information_sheet. pdf.

9.- Tesovic G. Lesnikar V. Aseptic meningitis after vaccination with L-Zagreb mumps strain - virologically confirmed cases. Vaccine 2006; 24: 6371-3. doi:10.1016/j. vaccine. 2006.06.025.

10.- Bonhoeffer J, Kohl Katrin, Chen R, Duclos P, Heijbel H, Heininger U, et al. The Brighton Collaboration - enhancing vaccine safety. Vaccine 2004; 22: 2046. doi:10.1016/j. vaccine.2004.01.016.

11.- Tozzi A, Asturias E, Ram Balakrishnan M, Halsey N, Law B, Zuber P. Assessment of causality of individual adverse events following immunization (AEFI): a WHO tool for global use. Vaccine 2013; 31: 5041-6. doi: 10.1016/j. vaccine.2013.08.087.

12.- ISP. MINSAL. Subdepartamento Farmacovigilancia. Agencia Nacional de
Medicamentos. ESAVI: 1902-00187. 9 de abril 2019. Documento no publicado.

13.- Hernández R, Giambalvo D, Montilla M, Morón D, Ghisays G. Diversidad antigénica de las vacunas antiparotidicas. Rev Inst Nac Hig Rafael Rangel 2013; 44: 46-51.

14.- Bonnet M, Dutta A, Weinberger C, Plotkin S. Mumps vaccine virus strains and aseptic meningitis. Vaccine 2006; 24: 7037-45. doi: $10.1016 /$ j.vaccine.2006.06.049.

15.- ISP. MINSAL. Subdepartamento Farmacovigilancia. Sección Información Medicamentos. Base de datos Nacional de Farmacovigilancia RAM-ESAVI y RED-RAM. Consulta 19-285. Documento no publicado.

16.- Demicheli V, Rivetti A, Debalini MG, Di Pietrantonj C. Vaccines for measles, mumps and rubella in children. Cochrane Database Syst Rev 2012 (2): CD004407. doi: 10.1002/14651858.CD004407.pub3.

17.- Saito H, Takahashi Y, Harata S, Tanaka K, Sato H, Suto T. Cloning and characterization of the genomic RNA sequence of the mumps virus strain associated with a high incidence of aseptic meningitis. Microbiology and Immunology 1998; 42: 133-7. doi: 10.1111/ j.1348-0421.1998.tb02262.x

18.- Cui A, Brown D, Xu W, Jin L. Genetic variation in the $\mathrm{HN}$ and $\mathrm{SH}$ genes of mumps viruses: A comparison of strains from mumps cases with and without neurological symptoms. 


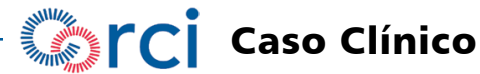

PLoS One 2013; 8: e61791. doi: 10.1371/ journal.pone.0061791.

19.- Mathakia M. An evaluation of the Rubini, Urabe AM9, and Jeryl-Lynn mumps vaccines, specifically concerning efficacy and association with aseptic meningitis. The Vaccine Revolution. June 5, 1998. Disponible en: https://web.stanford.edu/ siegelr/mathakia.html (Fecha acceso: diciembre de 2019)
20.- Sauder C, Vandenburgh K Iskow R, Malik T, Carbone K, Rubin S. Changes in mumps virus neurovirulence phenotype associated with quasispecies heterogeneity. Virology 2006; 350 : 48 -57. doi: 10.1016/j.virol.2006.01.035.

21.- Pan American Health Organization. World Health Organization regional office for the Americans. Programa ampliado de inmunizaciones. Precios de las vacunas para año 2019. Disponible en: https://www.paho. org/immunization-toolkit/spanish/?page_id=43 (Fecha de acceso: diciembre de 2019).

22.- Decreto $\mathrm{N}^{\circ} 3$. Titulo X: De la vigilancia Sanitaria. Párrafo Primero: De la Farmacovigilancia. Articulo $216^{\mathrm{a}}-220^{\mathrm{a}}$. Disponible en: https://www.leychile.cl/ Navegar?idNorma=1026879. (Fecha de acceso: diciembre de 2019). 